\title{
"Fala pouco e bem, ter-te-ão por alguém": escolarização, moralização e produção de sentido a partir das memórias de José Lins do Rego e Graciliano Ramos (Brasil, 1930-1945)
}

"Speak little and well, they will have you for someone": schooling, moralization and production of meaning from the memories of José Lins do Rego and Graciliano Ramos (Brazil, 1930-1945)

"Habla poco y bien, te tendrán por alguien": escolarización, moralización y producción de sentido a partir de la memoria de José Lins do Rego y Graciliano Ramos (Brasil, 1930-1945)

\author{
Katiene Nogueira da Silva \\ Universidade de São Paulo (Brasil) \\ https://orcid.org/0000-0002-1280-3041 \\ http://lattes.cnpq.br/8523522666926651 \\ katiene@usp.br \\ Roni Cleber Dias de Menezes \\ Universidade de São Paulo (Brasil) \\ https://orcid.org/0000-0001-8661-1328 \\ http://lattes.cnpq.br/2780596138885068 \\ roni@usp.br
}

\section{Resumo}

O artigo em tela se debruça sobre o processo de escolarização elementar no Brasil na primeira metade do século $\mathrm{XX}$, adotando como ângulo de observação a produção de sentido e os discursos de moralização contidos nas práticas de escolarização da infância. Para tal, privilegia o exame das memórias autobiográficas acerca das experiências escolares de dois escritores célebres da literatura nacional, José Lins do Rego e Graciliano Ramos, presentes, respectivamente, nos títulos Doidinho e Infância. Exemplares típicos dos romances de formação, os itinerários dos autores-personagens nos convidam a cruzar as memórias daquelas práticas de ensino com o desenho que apresentam das relações familiares, instituições escolares, imagens da profissão docente e das hierarquias e transformações sociais que caracterizam a sociedade brasileira do período.

Palavras-chave: Escolarização elementar. Romance de formação. Memórias autobiográficas. 


\begin{abstract}
The article on screen focuses on the process of elementary schooling in Brazil in the first half of the 20th century, adopting as an observation angle the production of meaning and the moralizing discourses contained in the practices of schooling in childhood. To this end, it privileges the examination of autobiographical memories about the school experiences of two famous writers of national literature, José Lins do Rego and Graciliano Ramos, present, respectively, in the titles Doidinho and Childhood. Typical examples of training novels, the author-character itineraries invite us to cross the memories of those teaching practices with the drawing they present of family relationships, school institutions, images of the teaching profession and the hierarchies and social transformations that characterize Brazilian society of the period.
\end{abstract}

Keywords: Elementary schooling. Training novel. Autobiographical memories.

\title{
Resumen
}

El artículo en pantalla se centra en el proceso de escolarización primaria en Brasil en la primera mitad del siglo XX, adoptando como ángulo de observación la producción de sentido y los discursos moralizantes contenidos en las prácticas de escolarización en la infancia. Para ello, privilegia el examen de las memorias autobiográficas sobre las vivencias escolares de dos célebres escritores de la literatura nacional, José Lins do Rego y Graciliano Ramos, presentes, respectivamente, en los títulos Doidinho e Infancia. Ejemplos típicos de novelas de formación, los itinerarios autor-personaje nos invitan a cruzar la memoria de esas prácticas docentes con el dibujo que presentan de las relaciones familiares, las instituciones escolares, las imágenes de la profesión docente y las jerarquías y transformaciones sociales que caracterizan a la sociedad brasileña del país. período.

Palabras clave: Escolaridad primaria. Novela de formación. Recuerdos autobiográficos. 


\section{Introdução}

Há alguns anos, em conferência proferida em um congresso sobre docência universitária na Argentina, Miguel Zabalza (2014) dizia que os professores, ao ministrarem as suas aulas, o fazem acreditando que estão colaborando para os alunos assentarem os tijolos que os ajudarão a construírem os pilares do conhecimento, mas, na prática, o que acontece é que os alunos recebem esses tijolos como se tivessem sido atirados nas suas cabeças e depois, cada um, a seu modo, resolve como lidar com isso. Ao pensar na relação entre a formação, a literatura e a aprendizagem, essa história foi lembrada, dizendo respeito às intenções dos professores e às experiências dos alunos. Especialmente nos primeiros anos da vida universitária, alguns termos proferidos com frequência nas aulas e com tanta familiaridade pelos professores em muitos casos não fazem, para alunas e alunos, o menor sentido. As perguntas poderiam resolver as dúvidas, mas, e esse é outro ponto importante, nem sempre se consegue fazê-las, pelos mais variados motivos: por timidez, por vergonha de perguntar algo que poderia parecer tão óbvio, por parecer que não se está autorizado a fazê-las ou simplesmente porque não se aprendeu ainda a formulá-las. Acredita-se que a leitura dos romances de formação pode contribuir para a aprendizagem por exprimir mediante relatos autobiográficos suas experiências formativas, evidenciando a articulação entre episódios vivenciados pelas personagens e a produção de sentido. O romance de formação é aquele cuja narrativa dedica-se a acompanhar um período de transição da vida da personagem, não apenas com relação ao amadurecimento biológico, mas também com relação à sua transformação psicológica e crítica que marcam as fases da sua existência. O termo é tradução do alemão, Bildungsroman, e teria sido utilizado pela primeira vez no início do século XIX, por Karl Morgenstern, professor de filologia clássica, que o associou ao romance de Goethe, $O s$ anos de aprendizado de Wilhelm Meister (MARTINI, 1972).

\section{"Não há aprendizagem sem história"}

O trabalho docente faz com que aquele que o exerce lide com as questões relativas à aprendizagem cotidianamente e, ao fazê-lo, o professor pensa também na sua própria aprendizagem, na sua história e no seu processo de formação, é o que sugere Maurice Tardif (2000) acerca da constituição dos saberes profissionais dos professores. Philippe Meirieu (1998), estudioso do tema, afirma que "não há aprendizagem sem história", ou seja, a aprendizagem implica na produção de sentido, no modo como cada sujeito, a partir das suas próprias experiências e da sua própria história, compreende o mundo que o cerca. A argumentação do autor é construída a partir da teoria construtivista, elaborada por Jean Piaget, e leva em conta, além da concepção de que há diferentes ritmos de aprendizagem, de que a compreensão vai muito além da repetição e da memorização, como já foi pensado um dia, ideia fundadora inclusive de muitas cartilhas e de muitos livros didáticos. Frases como "A vovó viu a uva", por exemplo, frequente nos referidos impressos utilizados em aulas de alfabetização, copiadas e repetidas pelos alunos, nem sempre poderiam ser tão instigantes a estes como, talvez, palavras soltas, apresentadas de forma fonética e depois silábica, acompanhadas de objetos e de estímulos sensoriais.

\section{A escola nos romances regionalistas: a produção de sentido}

No livro autobiográfico Infância, publicado em 1945, Graciliano Ramos recupera as suas memórias dos tempos de criança e juventude, a sua vida no sertão, as relações familiares e também a sua relação com a aprendizagem, assim como as suas experiências de escolarização. 
A relação do autor quando criança com os adultos, principalmente com os seus pais, é marcada pela opressão e pela tirania, expressa em castigos físicos e psicológicos, o que torna a leitura um tanto angustiante em muitos momentos. Aprender a ler e a escrever aparecem, na vida do menino Graciliano, como uma possibilidade de libertação daquele meio opressor no qual vivia e assim, logo no início do livro, ele conta sobre o primeiro contato que teve com uma escola. Em uma viagem feita de Alagoas ao sertão pernambucano, sua família precisou dormir pelo caminho e foi abrigada em uma escola. O menino, que tinha entre dois e três anos, viu que "um velho de barbas longas dominava uma negra mesa, e diversos meninos, em bancos sem encostos, seguravam folhas de papel e esgoelavam-se: - um $b$ com $a-b, a: b a$, um $b$ com um $e-b, e$ : be. Assim por diante, até $u$. (...) Tudo é bem nítido (...). Em pé, junto ao barbado, uma grande moça, que para o futuro adquiriu os traços de minha irmã natural, tinha nas mãos um folheto e gemia: - A, B, C, D, E." (p. 10) Nesse momento é como se o menino deixasse um certo estado de latência (ou estive adormecido) e começasse a compreender o mundo que o cercava, articulado às palavras e à aprendizagem. A irmã mencionada estaria entre aqueles que, no futuro, o apresentariam às práticas de alfabetização.

\section{"Fala pouco e bem: ter-te-ão por alguém"}

A sua relação com a leitura é iniciada com o seu pai, a quem ajuda em seu trabalho na mercearia da família, e que pretende alfabetizá-lo. Diz o menino:

Demorei a atenção nuns cadernos de capa enfeitada por três faixas verticais, borrões, nódoas cobertas de riscos semelhantes aos dos jornais e dos livros. Tive a ideia infeliz de abrir um desses folhetos, percorri as páginas amarelas, de papel ordinário. Meu pai tentou avivar-me a curiosidade valorizando com energia as linhas mal impressas, falhadas, antipáticas. Afirmou que as pessoas familiarizadas com elas dispunham de armas terríveis. Isto me pareceu absurdo: os traços insignificantes não tinham feição perigosa de armas. Ouvi os louvores, incrédulo. Aí meu pai me perguntou se eu não desejava inteirar-me daquelas maravilhas, tornarme um sujeito sabido como Padre João Inácio e o advogado Bento Américo. Respondi que não. Padre João Inácio me fazia medo, e o advogado Bento Américo, notável na opinião do júri, residia longe da vila e não me interessava. Meu pai insistiu em considerar esses dois homens como padrões e relacionou-os com as cartilhas da prateleira. Largou pela segunda vez a interrogação pérfida. Não me sentia propenso a adivinhar os sinais pretos do papel amarelo? (RAMOS, 1976, p. 102-103)

O pai do menino tentava despertar a sua curiosidade para a leitura e a escrita, que via com certa desconfiança a suposta liberdade que seria concedida pelo pai, sempre tão autoritário. E continua Graciliano sobre o episódio:

meu pai não tinha vocação para o ensino, mas quis meter-me o alfabeto na cabeça. Resisti, ele teimou - e o resultado foi um desastre. Cedo revelou impaciência e assustou-me. Atirava rápido meia dúzia de letras, ia jogar solo. À tarde pegava um côvado, levava-me para a sala de visitas - e a lição era tempestuosa. Se não visse o côvado, eu ainda poderia dizer alguma coisa. Vendo-o, calava-me. Um pedaço de madeira, negro, pesado, da largura de quatro dedos. (RAMOS, 1976, p. 104) 
Relembrando esses momentos, além do medo da punição do pai, a quem considerava "impossível contentar", caso não correspondesse ao esperado na realização das tarefas, o ato de decorar e repetir palavras e frases sem sentido lhe parecia uma insensatez. O côvado citado acima era a palmatória, objeto de madeira utilizado para punir fisicamente as crianças, batendo com ele nas palmas de suas mãos em caso de desobediência.

Quando o pai desistiu de ensinar o menino, sua irmã foi incumbida da tarefa, continuando a utilizar a cartilha para alfabetizá-lo que, além de explorar a repetição e a memorização dos elementos que levariam à aprendizagem, ainda era farta em frases que visavam à moralização das crianças, tais como: "A preguiça é a chave da pobreza", "Quem não ouve conselhos raras vezes acerta", "Fala pouco e bem: ter-te-ão por alguém”. O menino repetia mas não compreendia o sentidos das frases e dizia:

Esse Tertão para mim era um homem, e não pude saber que fazia ele na página final da carta. As outras folhas se desprendiam, restavam-me as linhas em negrita, resumo da ciência anunciada por meu pai.

- Mocinha, quem é Terteão?

Mocinha estranhou a pergunta. Não havia pensado que Tertão fosse homem. Talvez fosse. 'Fala pouco e bem: ter-te-ão por alguém'.

- Mocinha, que quer dizer isso?

Mocinha confessou honestamente que não conhecia Terteão. E eu fiquei triste, remoendo a promessa de meu pai, aguardando novas decepções. (RAMOS, 1976, p. 107)

O livro foi lido há quase vinte anos e esse trecho nunca foi esquecido pelos leitores que, sendo professores, sempre voltam a ele em suas aulas nas quais trabalham questões relativas à aprendizagem com os seus alunos.

\section{"Professor: é uma pessoa que não cansa de copiar (María José García, 8 anos)"}

Esse livro é retomado e o mencionado em aulas porque consideramos que a sua leitura, associada aos textos que lemos e às aulas que tivemos sobre ensino e aprendizagem ao longo de nossa formação ajudaram-nos a estabelecer relações e a compreender questões com as quais até então não havíamos lidado. Conforme assinalava Zabalza em sua conferência anteriormente mencionada, esse foi um livro que nos ajudou a lidar com os conteúdos trabalhados nas aulas e com a nossa produção de sentido em torno deles.

A teoria construtivista possui um conceito chamado descentragem, que diz respeito ao conflito de representações com os quais lidamos quando estamos num processo de aprendizagem. Desde que nascemos construímos representações acerca do mundo que nos cerca, sem tais representações nossa existência seria insuportável ou incompreensível a nós mesmos. É graças às nossas representações que elaboramos nosso modo de explicação e respondemos às perguntas que nos fazem desde bem pequenos, mesmo que não tenhamos estudado o tema e antes mesmo que tenhamos sido alfabetizados: o fazemos a partir da nossa imaginação, da nossa história e da nossa experiência. Gosto de pensar, de modo bastante ilustrativo, numa parede de escalada: as representações seriam os apoios que nos sustentam e permitem que nos movamos. E explicamos o motivo: se aprendemos a partir do conflito de representações e, segundo Meirieu, cada representação é um avanço e um obstáculo, nosso apoio é transitório, logo será substituído por outro, ou por outra representação novamente elaborada. Tal processo ocorre ao longo da nossa vida toda, é por isso que quando ouvimos algo que desconhecemos em geral respondemos com uma expressão de espanto: “Não é possível!”, “Você está brincando!”, “É verdade?”. Essas 
reações ocorrem porque não reconhecemos o que foi dito como possível ou existente, ou seja, como algo que faça parte das nossas representações.

Dessa forma, quando ensinamos lidamos constantemente com a situação na qual precisamos tornar familiar o que é estranho, tornar compreensível o que nem sempre o é ou naquele momento pode ainda não ser, precisamos estabelecer relações de modo que, a partir delas, aqueles que estão aprendendo possam encontrar elementos que os ajudem a produzir sentido. Se na universidade sabemos que os alunos chegam com representações constituídas acerca de conceitos e teorias abordados nas aulas, na escola não é diferente: as crianças também chegam à escola com representações consolidadas acerca do funcionamento do mundo que as cerca. Javier Naranjo (2013), professor colombiano, atento às explicações formuladas pelas crianças, escreveu um dicionário com as suas representações que vale a pena conhecer, chamado "Casa das estrelas: o universo contado pelas crianças". O título deve-se à explicação de uma criança sobre o que é o universo, para o menino de doze anos, é a "casa das estrelas". Perguntada sobre o que é um professor, a menina de oito anos responde: "é uma pessoa que não se cansa de copiar". Sobre o que é poesia, uma menina de dez anos responde: "tem vezes que alguém não tem nada pra fazer e começa a escrever poesias", enquanto outra de doze anos diz que é a: "expressão dos oprimidos". Estas são algumas definições que nos mostram representações das crianças sobre o mundo, mas também nos fazem pensar sobre os elementos aos quais elas se agarram para explicá-lo. A literatura pode ser um deles, um elemento importante ao qual podemos nos agarrar tanto para compreender o mundo que nos cerca e nós mesmos, como os conhecimentos que integram tanto os currículos escolares quanto universitários, produzindo sentido e tornando familiar aquilo que é estranho.

\section{Memórias autobiográficas e história da escolarização em Doidinho, de José Lins do Rego}

José Aderaldo Castello, em Memória e ficção: de Raul Pompeia ${ }^{1}$ a José Lins do Rego ${ }^{2}$ (1995), ao tomar os dois insignes literatos como exemplo e guia, alude aos artifícios empreendidos pelos narradores das tramas, por meio dos quais as personagens do enredo são erigidas (reconstruídas?) conforme uma projeção de tintas autobiográficas, em que as variações das relações tempo/memória são moduladas de maneira a, com a evocação desta última, instituir um tempo em que autor e personagem possam agir em simultaneidade. Não é outro juízo o que se extrai da abertura de O Ateneu, quando das recomendações do pai de Sérgio - Sérgio, o protagonista da história - a este último no momento em que o deixa no internato do diretor Aristarco: "“- Vais encontrar o mundo', disse-me meu pai, à porta do Ateneu, '- coragem para a luta!" Ao que acrescenta posteriormente Sérgio: "Eu tinha apenas onze anos". (Pompeia, 1996, p.3)

Para Castello (1995), as interdependências que são produzidas na narrativa entre autor e personagem indicam que o "ele', isto é, o personagem, em torno do qual se reorganiza o universo do autor, termina por aprisionar vivencialmente o "eu", ou seja, o próprio autor. Nesse encadeamento, ao tentar explicar para o "ele" (personagem) aquilo que o "eu" não compreendeu integralmente da infância à adolescência, o autor se reencontra no "ele", "a ponto de simbolicamente destruir o que passava a ser de ambos" (Castelo, 1995, p. 36), a saber, o universo que reorganiza a narrativa. O desencadear desse processo de interpendência entre autor e personagem levaria à criação de um duplo personagem central, ou antes acertadamente poderse-ia dizer o "duplo do personagem": de um lado o "ele", a criança que trilha os passos rumo à puberdade, já resultante do universo reorganizado, nas fronteiras delimitadas pelo internato, o qual é "definido pelo romancista como miniatura do mundo que estava lá fora" (Castelo, 1995,

\footnotetext{
${ }^{1}$ Escritor fluminense, nascido Raul d'Ávila Pompeia, em Angra dos Reis, em 12 de abril de 1863, e morto em 25 de dezembro de 1895, no Rio de Janeiro.

2 José Lins do Rego Cavalcanti nasceu no engenho de nome Corredor, no município de Pilar (PB), em 3 de junho de 1901, e morreu no Rio de Janeiro, em 12 de dezembro de 1957.
} 
p. 36); e de outro, o do próprio mundo situado para além da circunscrição do internato, em que se delineia uma imagem de adulto, sintetizada na figura do narrador, obstinado em reviver, explicar e debater os efeitos do internato sobre a criança/adolescente.

A memória, no mecanismo descrito acima, funciona não como recuperação de eventos ou mesmo uma mera reconstrução idealizada do passado, pelo qual um universo vivido é objetivado, mas em sentido diverso é tomada como "duração", instância processual de corte subjetivo que opera uma reorganização dos sentidos do vivido, ora perpetuando, alterando ou suprimindo os quadros mentais provenientes da mescla entre experiência e imaginação.

Em Doidinho, José Lins do Rego nos dá a ver tal movimento de interdependência entre autor e personagem, em que a memória é ativada para reorganizar o universo do vivido. O internato, "mundo em miniatura" (e o termo é cunhado por Raul Pompeia n' "O Ateneu"), é o cenário principal em que essa memória é acessada, e, especialmente para os interesses das reflexões que se descortinam a seguir, representa a elevação do estatuto que a escolarização, de um lado, e a própria escola, de outro, desempenhavam no conjunto da formação educativa disponível àquelas crianças e jovens dos últimos decênios do século XIX e primeira metade do XX.

Há, todavia, algumas diferenças a serem salientadas entre Pompeia e Lins do Rego e entre $O$ Ateneu e os dois primeiros volumes do "ciclo da cana-de-açúcar" 3 . Além dos aspectos internos a cada uma das obras, das referências literárias distintas, dos itinerários diferentes e do modo peculiar em que estes transpareciam nas respectivas escritas, percebe-se na narrativa que caracteriza Menino de engenho e Doidinho um tom agreste e rude, próprio das relações sociais que são travadas entre os atores que compunham a "sociedade do engenho". Aqui adquire relevância primeira as representações de infância que caracterizam os personagens Sérgio e Carlos de Melo. O personagem Sérgio remete ao modelo da criança burguesa do século XIX, culminância de um processo de definição da infância das camadas mais prósperas da sociedade, a qual, de acordo com Ariès (2006), iniciando-se ainda na passagem da Idade Média para a Idade Moderna, produz um sentimento novo em relação aos indivíduos de tenra idade, em que aspectos como o cuidado, o alheamento do mundo (dos espaços públicos e comuns) e a imprescindibilidade de uma educação condizente com seu estágio de desenvolvimento vão se processando de modo a demarcar as fronteiras de tais agrupamentos etários e daqueles reconhecidos como dos adultos.

A infância de Carlinhos, vivida dos quatro aos doze anos ${ }^{4}$ no engenho Santa Rosa, de propriedade de seu avô materno, José Paulino, é recheada de eventos que o iniciam no mundo das coisas e dos homens, característica que atua como pano de fundo, como contraste constante face àquele "mundo em miniatura" representado pela escola do "Seu Maciel". As primeiras impressões da instituição, compartilhadas com o leitor já nas primeiras linhas do romance, ultrapassam o contraste a que se referiu há pouco: dão o tom de ruptura com a cornucópia de afetos de que era exemplo o Santa Rosa.

"- Pode deixar o menino sem cuidados. Aqui eles endireitam, saem feitos gente" - dizia um velho alto e magro para o meu tio Juca, que me levara para o colégio de Itabaiana. Estávamos na sala de visitas. Eu, encolhido numa cadeira, todo enfiado para um canto, o meu tio Juca e

\footnotetext{
${ }^{3}$ Doidinho (1933) sucede Menino de engenho (1932) no convencionado “Ciclo da cana-de-açúcar”, série de 5 composições em que Lins do Rego possibilita ao leitor entrever os dramas cotidianos no microcosmo social das regiões produtoras de açúcar do Nordeste do Brasil, numa leitura articulada às transformações mais gerais dessa região. Além desses dois títulos, o ciclo é integrado por Banguê (1934), Usina" (1936) e "Fogo Morto" (1943). Barbosa Filho (2005), indica que interior ao ciclo se encerra uma trilogia - consubstanciada por "Menino de Engenho", "Doidinho" e "Banguê" - a qual abrange três das "idades da vida" do personagem Carlos de Melo protagonista em todos os três títulos: infância, adolescência e a vida adulta.

${ }^{4}$ Esse período da vida de Carlinhos é dado a conhecer em Menino de engenho (1932).
} 
o mestre. Queria este saber da minha idade, do meu adiantamento. O meu tio informava de tudo: doze anos, segundo livro de Felisberto de Carvalho, tabuada de multiplicar.

(...) E o meu tio me chamou para o abraço. Parecia que me deixava de vez, porque foi com o coração partido que me cheguei para perto dele.

“- Estude. Em junho venho lhe buscar." Saí chorando. Era a primeira vez que me separava de minha gente, e uma coisa me dizia que a minha vida entrava em outra direção. (Lins do Rego, 2011, p. 1-2)

O tom memorialístico das obras que compõem a "saga" de Carlos de Melo se depreende da caracterização das paisagens e dos personagens de Menino de engenho, Doidinho e Banguê. Órfão de mãe já no ano do seu nascimento, José Lins do Rego fica entregue aos cuidados de sua tia Maria e do seu avô, figura que vem a imortalizar na persona do Coronel José Paulino, personagem marcante na ação dos três romances aludidos, exatamente os três primeiros de sua carreira de escritor. Tendo perdido logo cedo também a tia - "mãe substituta" - vai estudar no Internato Nossa Senhora do Carmo, na cidade de Itabaiana, Paraíba, onde inicia sua vida escolar, o mesmo onde se desenrola a trama de Doidinho.

No seu segundo romance, as "recordações" do narrador onisciente se revestem de ternura e de intensa humanidade. Nele as palavras não parecem transpirar rancor, mas antes ressoam a nostalgia da atmosfera do engenho, ambiente que exalava o clima de decadência da "civilização açucareira", tão bem captada pela pena de José Lins do Rego no trabalho de tipificação social que realiza por meio da recuperação da vida concreta e de uma certa psicologia dos personagens criados. E mesmo o internato, com todas as limitações que impôs ao menino que adentrava a adolescência, limitações distintas daquelas que regravam a vida no engenho, produziram em Carlinhos um efeito diverso do que em Sérgio, já que ao fim e ao cabo o internato, mesmo com luzes e tonalidades peculiares, não destoa do quadro amplo daquela sociedade patriarcal encimada pelo engenho, produtor de sociabilidades que ordenavam a mundivivência tanto dos habitantes dos estabelecimentos produtores de açúcar quanto da extensa malha social que em grande medida destes era dependente.

É, pois, em "Doidinho", por ser o livro intermediário entre "Menino de Engenho" e "Banguê", representando assim o final da infância e a vivência da adolescência, que Lins do Rego estabelece a unidade do mundo restaurado de suas rememorações do rincão natal e dos sujeitos modelares que o povoavam. De certa forma, residem aí as raízes das imagens das "origens", as quais são repassadas, reconstruídas e classificadas pela memória do adulto. $\mathrm{O}$ internato, paisagem central do romance, como um microcosmo, apresenta-se ao "ele" como uma escola, além do que efetivamente era, ou seja, como um estabelecimento de ensino, mas adicionalmente como "escola de vida", já de outro jaez daquela escola - essa sim, metafórica representada pelo engenho. No "mundo em miniatura" o "ele" personagem deparava-se, testemunhava e experimentava a lealdade, a amizade, a traição, a intriga, o sexo, o medo, a injustiça, a proteção, todos esses sentimentos e circunstâncias envoltos na complexa trama das alianças, concorrências e favorecimentos executados pelos atores vinculados ao internato, capitaneados pelo despotismo severo e iníquo do Seu Maciel, diretor da instituição.

Transpostos para o terreno da escolarização no Brasil, o enredo de José Lins do Rego em "Doidinho" focaliza a formação do futuro senhor de engenho, segundo uma visão nitidamente idealizada: a do mandatário local que detém o poder tanto em decorrência de sua condição de nascimento quanto do verniz intelectual adquirido na escola, ainda que ambas esferas estejam interligadas, pois se percebe a intenção do romancista em circunscrever o personagem que encarna esse arquétipo - seu avô materno - com o avô do personagem Carlos de Melo, o velho José Paulino, sujeito venerando por uma sabedoria que vem da coisas práticas do mundo do engenho, mas também do universo da cultura letrada. A consciência, todavia, do 
desmoronamento daquela "civilização do açúcar" perpassa os romances dessa fase de Lins do Rego. Com isso, o tipo de mando e as relações de poder que emanam da configuração piramidal da sociedade de que provinha por origem - a mesma de seus personagens ficcionais atravessava um período de transformação, entrando em declínio em função da concorrência de novas formas, idealmente menos personalistas, de exploração econômica dos recursos da terra. Trata-se aqui da usina, complexo tecnológico que, à semelhança do que desempenhara para o Velho Oeste estadunidense a chegada da ferrovia, brilhantemente enfocada em The man who shot Liberty Valance ${ }^{5}$, inaugura um novo tempo, sentido de maneira amarga por Carlinhos no epílogo de Menino de Engenho (1932) quando o mundo de sua infância é tragado pela superação inexorável de que aquele estabelecimento é portador. A escola de Carlinhos, em situação diversa da vivida pelo engenho, não aparenta, nas tintas com que é descrita por Lins do Rego, sinais de mudança iminente. As práticas pedagógicas, os instrumentos de disciplinamento, a organização do espaço, as relações professor-aluno e a rigidez dos métodos de ensino estão insertas num enquadre temporal de quase imutabilidade. A descrição da cidade e dos arredores do internato que é dada a ver nos passeios realizados por Carlinhos comprovam, em generalidade, essa percepção. Se na prática cumprem a função de liberar, ao menos fugaz e parcialmente, o personagem central do romance do ambiente claustral da escola e dos constrangimentos a ele, as atividades realizadas e experiências obtidas no espaço exterior assinalam eventos matizados pela estática, espécie de moldura pela qual as repetidas fórmulas de ensino, disciplinamento e introjeção dos sentidos da cultura letrada adquiriam tons mais vibrantes. O desajuste entre a educação oferecida e as expectativas do aluno, circunscritas aqui ao plano da experiência concreta no interior da instituição - não ao que ela franqueava como signo de distinção social -, ratificava um quadro de paralisia do modo como era compreendida a função social da escola pela população do lugar: a de "endireitar" os desajustados e incapazes, algo, inclusive, que Carlinhos de forma até decepcionada diagnosticava como intenção frustrada em relação a ele próprio, como se depreende da passagem:

"- A senhora não imagina que trabalho deu. Alunos destes não pagam o trabalho (mencionando outro aluno interno). Este, não (referindo-se a Carlinhos). Só tem mesmo esta peitica com os exercícios. Adiantouse muito aqui. Avalie a senhora que chegou no segundo livro e já está no segundo grau."

Mas não me contentavam estes elogios. A verdade dura estava às vistas de todo o mundo. Somente eu era que não tinha jeito. (REGO, 2011, p.134)

Comparada, pois, com as instituições legadas pelo século XIX, a escola frequentada por Carlinhos, em história que se passa em momento indeterminado da Primeira República, período em que transcorrem as tramas de Menino do engenho e Doidinho, é dada a ver, em certo sentido, em discrepância com o fluxo temporal que marca a sociedade açucareira, distinguido em larga medida pela dinâmica de um mundo que se extinguia para o surgimento de outro. Se o mundo reorganizado pela memória de José

${ }^{5}$ Filme dirigido por John Ford, produzido por Wilis Goldbeck e lançado pelos Estúdios Paramount em 1962. Foi estrelado por John Wayne, James Stewart, Vera Miles e Lee Marvin. No Brasil recebeu o título $O$ homem que matou o facínora. Esquematicamente, narra a história dos sucessos experimentados por um advogado recém-formado, Ranse Stoddard (personagem vivido por James Stewart), proveniente da costa leste, que se estabelece numa localidade do far-west estadunidense da segunda metade do século XIX. A trama destaca a introjeção dos arquétipos burgueses que caracterizavam o Leste nos territórios do Oeste, tipificada em primeiro plano pela primazia da lei sobre a força e pela valorização da instrução e da cultura letrada. Antes que representar exclusivamente uma marca civilizatória, a introdução de tais arquétipos é apresentada em tom pessimista, como uma despedida sentimental em relação a um sujeito e a uma formação histórico-social a partir daquele momento desaparecidos. 
Lins do Rego trata de evocar as memórias afetivas de um tempo e uma sociabilidade em franco processo de ultrapassagem, a escola, antes que dispositivo em que se veem representados os componentes da mudança social, econômica e cultural, cumpre mais a função de moldura para o reencontro com uma dimensão afetiva estilizada e idealizada.

\section{Considerações Finais}

Infância e Doidinho são dois romances de formação que muito dizem à história da educação brasileira. Por um lado, ambos guardam traços, no campo da literatura, das transformações pelas quais passavam as ciências humanas e sociais no Brasil depois dos anos 1930. Se é fato que já se pode reconhecer na história da literatura nacional desde a segunda metade do século XIX até os dois primeiros decênios do século XX obras que se debruçam sobre fenômenos ligados à formação social e histórica brasileira, realizando até, em alguns casos, uma sociologia avant la lettre, os dois romances regionalistas em tela trazem a marca de um profundo interesse em "interpretar" o país, conjugando contribuições do ensaísmo modernista e do pensamento social de base acadêmica que ganhava força no Brasil no período e, ainda, reverberando, a seu modo, traços do amplo movimento verificado em diferentes modernismos nacionais nas primeiras décadas do século XX (especialmente nos domínios da literatura, música e artes plásticas), qual seja o de buscar uma compreensão das manifestações culturais do que se entendia por "povo", dos caracteres e personagens que integravam os diferentes perfis nacionais, mas que permaneciam sombreados pela onipresença dos modelos culturais estrangeiros.

Foi nessa atmosfera que os dois romances em tela irromperam. De modo esquemático eles sugerem já as contradições da sociedade brasileira dos anos 1930 e 1940, em que se divisava um país urbano, industrializado, moderno, face a estruturas arcaicas, marcadas por relações de tipo senhorial, com predominância do patriarcado e resquícios de práticas escravistas, adstritas em maior medida ao meio rural e às zonas empobrecid as e decadentes do território. Tais temáticas são vistas fundidas ao universo psíquico dos personagens de ambos os livros, não conforme um mecanismo determinista, em que aqueles nada mais fossem que resultado do meio, mas as "leituras de mundo" realizadas pelos autores-personagens descortinam ao leitor os processos de impregnação nesse sujeito duplo do peso das estruturas políticas, econômicas, sociais e culturais nos cenários em que se move. Nesse sentido, a presença destacada da escola em Doidinho e Infância, ao mesmo tempo em que focaliza o que socialmente era esperado da instrução nos seus componentes formativos e disciplinares, entreabre dispositivos da dimensão subjetiva do aluno - mediado, evidentemente, pela memória do autor -, desafiando o historiador da educação a reimaginar o que era ser aluno de uma escola elementar nas primeiras décadas do século XX no Brasil. Na esfera das representações, ambos autores desenham um quadro sugestivo da percepção acerca do estatuto profissional docente, dos processos de configuração da categoria aluno, da dimensão moralizante do ensino, dos compêndios e materiais utilizados, dos métodos de ensino empregados, da composição, organização e hierarquização dos saberes escolares, da disposição dos espaços e tempos, da liturgia enfim, na acepção conferida por Boto (2014), que notabiliza a escola moderna.

Adicionalmente, a reconstituição ficcional dos itinerários estudantis e de iniciação no mundo letrado dos autores-personagens empreendida pelos dois romances de formação, não apenas enriquece o caudal de fontes com que conta o historiador da educação, bem como dá azo a investimentos de cunho metodológico, em que abordagens alicerçadas na exploração de obras literárias e de natureza memorialística e autobiográfica venham a fertilizar ainda mais os estudos sobre nosso passado educativo. 


\section{Referências}

ARIÈS, P. História social da criança e da família. $2^{\text {a }}$ ed. Trad. Dora Flaksman. Rio de Janeiro: LTC, 2006.

BARBOSA FILHO, H. José Lins do Rego: técnica narrativa de Fogo Morto. Revista Brasileira, Fase. VII, Ano XI, n. 42, p. 51-72, jan./fev./mar. 2005.

BOTO, C. A liturgia da escola moderna. Saberes, valores, atitudes e exemplos. História da Educação, Porto Alegre, v.18, n.44, p.99-127, set./dez. 2014. DOI: https://doi.org/10.1590/S2236-34592014000300007

CASTELLO, J. A. José Lins do Rego: modernismo e regionalismo. São Paulo: EDART, 1961. CASTEllo, J. A. Memória e ficção: de Raul Pompeia a José Lins do Rego. Remate De Males, Campinas, 15(1), 33-46, 1995.

MEIRIEU, P. Aprender... sim, mas como? Porto Alegre: Artmed, 1998.

MARTINI, F. História da literatura alemã: do romantismo à actualidade. Lisboa: Estúdio Cor, 1972.

NARANJO, J. Casa das estrelas: o universo contado pelas crianças. Rio de Janeiro: Foz, 2013. POMPEIA, R. O Ateneu. 16ª ed. São Paulo: Ática, 1996.

RAMOS, G. Infância. Rio de Janeiro: Record; São Paulo: Martins, 1976.

REGO, J. L. do. Doidinho. 47ª ed. Rio de Janeiro: José Olympio Ed., 2011.

REGO, J. L. do. Menino de engenho. 80ª ed. Rio de Janeiro: José Olympio Ed., 2001.

TARDIF, M. Saberes profissionais dos professores e conhecimentos universitários: elementos para uma epistemologia da prática profissional dos professores e suas consequências com relação à formação do magistério. Revista Brasileira de Educação, n.13, p.5-24, jan./mar. 2000.

ZABALZA, M. Los fundamentos de la didáctica universitaria. La Didáctica Universitaria como integración de saberes y voluntades. Conferência. Rosario: CIDU, 2014. 